\title{
New insights into bone morphogenetic protein signaling: focus on angiogenesis
}

\author{
Isabel Moreno-Miralles ${ }^{\mathrm{a}}$, Jonathan C. Schisler $^{\mathrm{a}}$, and Cam Patterson ${ }^{\mathrm{a}, \mathrm{b}}$ \\ ${ }^{a}$ Carolina Cardiovascular Biology Center, University of North Carolina, Chapel Hill, North \\ Carolina, USA \\ ${ }^{b}$ Department of Medicine, University of North Carolina, Chapel Hill, North Carolina, USA
}

\section{Abstract}

Purpose of review-The role of bone morphogenetic proteins (BMPs) in vasculogenesis is still not well understood, despite many recent developments in this area of research. In this review, we discuss the most recent studies that identify new critical mechanisms through which BMP signaling acts with a focus on angiogenesis.

Recent findings-New evidence brought to light over the last few years suggests that BMPbinding proteins, formerly thought of as antagonists, can also increase BMP activity under certain conditions. It has also recently been determined that components of the extracellular matrix are involved in the BMP signaling pathways that regulate angiogenesis. Through the BMP pathway, myosin- $\mathrm{X}$ and cyclooxygenase 2 serve as target genes that have been determined to play a role in blood vessel formation. BMPs also conduct Smad-independent signaling and crosstalk with other pathways. Finally, BMPs have been shown to play an antiangiogenic role in specific settings.

Summary-Better understanding of the BMP signaling pathway and its regulators can have potentially great effects on therapeutic strategies from cardiovascular disease to cancer.

\section{Keywords}

angiogenesis; bone morphogenetic protein; bone morphogenetic protein endothelial cell precursorderived regulator; cyclooxygenase 2; endothelial cells; extracellular signal-regulated kinase; gremlin; matrix gamma-carboxyglutamate protein; micro-RNA; myosin-X

\section{Introduction}

Bone morphogenetic proteins (BMPs) belong to the transforming growth factor $\beta$ (TGF $\beta$ ) superfamily of extracellular signaling proteins and were initially described for their ability to induce ectopic bone and cartilage formation [1]. BMPs are required for mesoderm formation and consequently for the development of all mesodermally derived tissues, including blood vessels [2,3]. Mice defective in Smad 1 or Smad 5 (integral components of the BMP signaling cascade) die in utero due to defective vasculature formation [4-7]. After birth, BMPs are critical for maintenance of angiogenesis through regulation of vascular endothelial growth factor (VEGF) [8]. 
A variety of regulatory mechanisms have been described and many excellent reviews have been published on the BMP signaling pathway. However, new layers of complexity are constantly being added to the network of regulators and effectors underlying the BMP pathway, reflecting the fine-tuning of this signaling pathway to specific developmental requirements. This review focuses on recent advances in our knowledge of the regulation of angiogenesis by BMPs.

\section{New roles for extracellular bone morphogenetic protein antagonists}

Numerous extracellular BMP antagonists have been described; on the basis of protein sequence alignment, these can be categorized into subgroups, including noggin, the chordin family, twisted gastrulation, and the Dan family [9]. BMP antagonists bind with high affinity to BMPs and have been shown to prevent the interaction of BMP proteins with their cognate receptors. However, recently published studies have also described 'agonist' activities of several formerly known BMP antagonists. For example, twisted gastrulation, when expressed at high levels in the presence of xolloid, exerts a 'pro-BMP' signal on developing Xenopus embryos [10]. In Drosophila, the secreted BMP antagonist short gastrulation (Sog, homolog of chordin) is also capable of enhancing signaling by transporting BMPs through tissues [11]. Determining the circumstances under which a BMP-binding protein acts as an antagonist or agonist has been quite a challenge. However, accumulating data suggest that some of the factors that help determine the effect on BMP signaling include concentration of the binding protein, the identity of the BMP ligand involved, and the developmental stage and characteristics of the cell types involved. The evidence supporting a dual role for two traditional BMP antagonists, BMP endothelial cell precursor-derived regulator (BMPER) and gremlin, are described below.

\section{Bone morphogenetic protein endothelial cell precursor-derived regulator}

BMPER, also known as crossveinless-2 (CV2), is attributed both pro and anti-BMP signaling effects [12-17], although the mechanism behind this dual action is uncertain. Growing evidence suggests that the concentration of BMPER relative to BMP may determine the nature of its effect on signaling. Studies from our laboratory demonstrate that the ratio of BMP4 to BMPER modifies the intracellular response to BMP4. Low BMPER concentrations lead to an increase in p-Smad1/5/8 levels, whereas excess BMPER inhibits BMP4-mediated phosphorylation of Smads (Kelley et al., in preparation) (Fig. 1a). Similarly, in Drosophila posterior crossvein (PCV) formation experiments, moderately increasing expression of a BMPER transgene results in a slight gain in signaling (occasional formation of additional veins), whereas continuing to increase expression levels eventually blocks PCV formation, similar to knocking-out BMPER in this system [18*0. Similar dosedependent effects of BMPER have been observed in several in-vivo angiogenesis assays, including sprouting and migration of human umbilical vein endothelial cells (HUVECs), development of chick embryo chorioallantoic membrane capillary networks, and invasion of mouse subcutaneous endothelial cells in Matrigel plug experiments. In all these cases, low BMPER concentrations enhance sprouting and vasculature formation, whereas high concentrations inhibit it. In addition, silencing endogenous BMPER or BMP4 inhibited HUVEC cell sprouting and migration, indicating that their proangiogenic function in these assays is dependent on each other's presence $\left[19^{\circ}\right.$ ].

Different hypotheses have been put forward to explain BMPER's ability to act as either an agonist or antagonist of BMP signaling. According to one model, when BMPER binds to BMP2 it overlaps with the BMP2 epitope that interacts with the type II receptor interaction while at the same time covering most of the hydrophobic patch of the epitope required for type I receptor binding [20]. Interestingly, in alkaline phosphatase assays and RNA injections in zebrafish embryos, BMPER mutants that fail to interact with BMP2 lose their 
anti-BMP activity (dorsalization), whereas the weak pro-BMP action observed in zebrafish (weak ventralization) appears independent of BMP-BMPER interaction. These results lead to the conclusion that blocking BMP's interaction with its receptor is the inhibitory mechanism used by BMPER under these circumstances, whereas BMPER's pro-BMP effects appear to be independent of BMP (Fig. 1b). Other studies, however, suggest that the mechanism of BMPER's dual action may not be as simple as blocking the interaction of BMP with its receptor. In Drosophila, CV2 binds Dpp (BMP2/4 homolog) and Gbb (BMP7 homolog) as well as the receptor thickveins (BMPR-I homologous), indicating that a ligandreceptor interaction is still possible in this case even in the presence of BMPER.

Furthermore, Dpp can interact with both CV2 and BMPR-IB simultaneously [18*0. Another indication that there may be one or more mechanism involved in BMPER's regulation of BMP signaling comes from studies carried out in our laboratory. We have data indicating that BMPER inhibits BMP signaling in mouse intraembryonic endothelial cells (MECs) by inducing clathrin-mediated endocytosis of the complex BMPER-BMP-BMPR (Kelley et al., in preparation) (Fig. 1a).

Mathematical models that take into account the calculated dissociation constant values for different BMPs, BMPER, and the receptors suggest that BMPER might display different responses (i.e. agonist versus antagonist) depending on the isoform of BMP with which it is interacting. In S2 cells, excess BMPER blocks Dpp and Gbb signaling, whereas reducing endogenous BMPER by RNAi increases Dpp signaling but reduces Gbb signaling by 20 $30 \%$ [18*0. Surprisingly though, in the early Drosophila embryo, where a different set of BMP ligands act, loss of endogenous BMPER actually expands BMP signaling, opposite to the effects of BMPER loss in the PCV $\left[18^{\circ *}\right]$. Therefore, BMPER concentration and the type of BMP present appear to determine whether BMPER promotes or inhibits BMP signaling. This could be explained by a model whereby BMPER, at moderate levels, could move BMPs from the extracellular space onto receptors via the complex BMP-BMPER-BMPR, whereas, at higher levels, BMPER antagonizes signaling by sequestering BMPs in the complex (Fig. 1a).

Yet another potential mechanism of action recently proposed involves BMPER antagonism of chordin actions through direct interaction. In Xenopus embryos BMPER acts as a local BMP feedback inhibitor. However, when chordin levels are increased, BMPER can exert pro-BMP effects via some form of chordin antagonism, whereas loss of BMPER enhanced overexpressed chordin anti-BMP activity (Fig. 1b) [21 $\left.1^{\circ}\right]$.

\section{Gremlin}

Gremlin, a potent BMP inhibitor, exerts its anti-BMP signaling effects by binding BMPs in such a way that interaction with BMP receptors is no longer possible (Fig. 1b) [22]. Gremlin can also inhibit BMP signaling by interacting with the BMP4 precursor protein thereby preventing the secretion of mature BMP4 (Fig. 1c) [23]. However, similar to BMPER and other so-called BMP antagonists, gremlin has also been shown to be capable of proangiogenic activity, in this case though, through BMP-independent mechanisms. In subcutaneous microvascular endothelial cells, gremlin interacts with an unknown membrane protein to induce the phosphorylation of focal adhesion kinase, paxillin, and extracellular signal-regulated kinase (ERK)1/2, resulting in a proangiogenic effect (Fig. 1c) [24 $4^{\circ}$. Gremlin can also specifically upregulate angiopoietin-1 (Ang-1) expression (but not Ang-2, Tie-2 receptor, or VEGFA) in endothelial cells, resulting in a proangiogenic effect that appears to be mediated via the activation of nuclear factor-kappa B (NF- $\mathrm{kB}$ ) [25]. As mentioned, these interactions are not influenced by BMP4. 


\section{Extracellular matrix components involved in bone morphogenetic protein signaling}

Although extracellular matrix (ECM) proteins are often considered to be just 'scaffolding' outside the cell, recent reports have uncovered a crucial role for them in the regulation of TGF $\beta$ signaling and, more recently, BMPs in the vascular system. ECM proteins immobilize TGF $\beta$ proteins in the extracellular space before they have a chance to bind to receptors on the cell surface, thereby regulating the bioavailability of TGF $\beta$ [26]. A similar relationship between BMP signaling and the ECM component matrix gamma-carboxyglutamate protein (MGP) has also been described [27]. MGP, an inhibitor of tissue and vascular calcification, is expressed in endothelial cells where it appears to play a key role in maturation of vasculature. In bovine aortic endothelial cells (BAECs), MGP can increase expression of VEGF by enhancing TGF $\beta$ signaling through the receptor activin receptor-like kinase 1 (ALK1) [28]. However, in the same cells, a progressive increase of MGP levels ceases to be stimulatory and instead turns inhibitory. It has been suggested that a novel regulatory pathway involving BMPs may mediate this biphasic effect of MPG. BMP2 and BMP4 induce the expression of ALK1 in a dose-dependent fashion, and ALK1, when activated by TGF $\beta$, induces expression of MGP in addition to VEGF. Interestingly, low-to-intermediate doses of MGP enhance ALK1 signaling, thereby providing positive feedback to this system. However, when the concentration of MGP increases, it binds and inhibits BMP2 and BMP4, thus providing negative feedback for BMP signaling, which ultimately leads to a decline in ALK1 and VEGF expression (Fig. 2a) [29]. These findings demonstrate that the relationship between BMP and the ECM protein MGP is critical in the regulation of endothelial growth and proliferation and, as such, tight feedback loops exist within this pathway to ensure appropriate cellular responses.

\section{Myosin-X and cyclooxygenase 2 are bone morphogenetic protein target genes involved in blood vessel formation}

BMPs are well known potent angiogenic factors in mouse embryonic stem cells [15,30], Xenopus embryos [31], as well as in-vitro assays [32]. In addition, BMP2 and BMP4 can enhance neovascularization in tumors [33-35]. However, only VEGF and Id1 had been identified as angiogenic downstream BMP target genes [8,32], rendering the mechanisms by which BMPs induce vascular development relatively unknown. Using information gleaned from gene expression analysis of BMP-stimulated MECs, our laboratory recently identified two new direct BMP target genes involved in angiogenesis. The first is cyclooxygenase 2 ( Cox 2), which catalyses the conversion of arachidonic acid to prostaglandins. BMP6 induces Cox 2 expression as well as production of prostaglandins in a Cox2-dependent fashion. We found that Cox 2 mediates BMP6-induced endothelial cell proliferation, migration, and network assembly as well as microvessel outgrowth in aortic rings [36]. These results are in agreement with the association of $\operatorname{Cox} 2$ with several physiologic and pathologic pathways that participate in angiogenesis, inflammation, and invasiveness [37,38].

In addition to $\operatorname{Cox} 2$, we also demonstrated that both BMP6 and BMP2 are powerful inducers of myosin-X $(M y o X)$ expression, an unconventional myosin critical for filopodial formation. BMP6-mediated induction of $M y o X$ is necessary for filopodial formation, cell alignment, directed migration, and tube formation in MECs. In addition, $M y o X$ colocalizes with the BMP receptor ALK6 in the filopodia, and is necessary for activation of Smads, suggesting that $M y o X$ mediates localization and amplification of BMP responses in endothelial cells $\left[39^{\circ}\right]$. 


\section{Bone morphogenetic protein Smad-independent signaling and crosstalk with other pathways}

Traditionally, BMP signaling pathways have been reported to involve Smad phosphorylation and direct transcriptional regulation of target genes. However, recent studies [40,41] have identified new routes of BMP signaling as well as modulation of BMP signaling by crosstalk with other pathways.

In addition to the canonical Smad phosphorylation pathway, BMPs can also activate Erk, Jun N-terminal kinase (JNK), and p38 mitogen-activated protein kinase (MAPK) pathways to influence embryonic development and bone formation [41,42]. Recently, Erk phosphorylation in endothelial cells was implicated for BMP4-induced capillary sprouting (Fig. 2b) [43"]. Although BMP4 activates Erk phosphorylation in this assay, strikingly, Smad-mediated signaling is not required for sprouting. However, Smad and Erk pathways do communicate through signal crosstalk as overexpression of the inhibitory Smad6 inhibits Erk phosphorylation and Erk-induced capillary sprouting (Fig. 2b) [43" $]$.

Furthermore, it is now well accepted that Erk/MAPK can regulate Smad-mediated signaling. However, the end result of this Erk pathway signaling appears to depend on the cell type involved and target gene specificity, with both enhanced and inhibitory Smad activity being reported by various groups [44-46]. For example, Smurf1 (an E3 ubiquitin ligase) selectively recognizes the MAPK-phosphorylated linker domain of Smad1 and polyubiquitinates the protein, leading to its degradation and subsequent inhibition of activity [47]. However, a recent study [48 ${ }^{\circ}$ indicates that Smad1 degradation requires subsequent glycogen synthase kinase 3 (GSK3) phosphorylation in the linker domain, and pSmad activity can be rescued by Wnt signaling inhibition of GSK3 (Fig. 2c). Little is known about the effects of this mode of Smad regulation in angiogenic processes.

Finally, BMP signaling can also be mediated through the regulation of micro-RNA (miRNA) maturation [49*]. miRNAs are endogenous, small, noncoding RNAs that regulate gene expression at the posttranscriptional level, and recent findings provide evidence of a direct link between BMP/TGF $\beta$ signaling and miRNA regulation in human vascular smooth muscle cells. Upon stimulation, phosphorylated R-Smads physically interact with the primary miRNA processing machinery in the nucleus. This interaction leads to an increase in mature miRNAs, particularly miR-21, through a not yet defined mechanism (Fig. 2d). This new mechanism of Smad-mediated BMP signaling is receiving a lot of attention because of the fact that recent research shows that miRNAs can regulate heart and vascular development [50], opening up exciting new therapeutic possibilities in the treatment of cardiovascular diseases.

\section{Bone morphogenetic protein: the antiangiogenic role}

As well known as BMPs are for their ability to stimulate angiogenic processes, several reports have shown that BMPs can also play a role in inhibiting angiogenesis. In a mouse model of hypoxia-induced neovascularization of the retina, BMP2 and BMP4 are downregulated soon after the onset of hypoxia, a process that appears necessary for subsequent tissue repair and neovascularization [51]. In an in-vitro angiogenesis assay with endothelial cells, BMP4 was found to exert an antiangiogenic influence, which could be reversed by the addition of chordin-like 1 [52]. In the vasculature of the rat papillary membrane (a transient vasculature in developing mammals), BMP4 induces apoptosis and regression. In addition, lens-conditioned medium obtained from rats induces apoptosis in endothelial cells and inhibits endothelial tubulogenesis, effects that can be blocked by both Noggin and the BMP4-specific neutralizing antibody [53]. However, not all endothelial cells 
undergo apoptosis when treated with BMP4. Although capillary and venous cells appear to be sensitive to the antiangiogenic effects of BMP4, coronary arterial cells are immune, suggesting that differential expression of inhibitory Smad proteins protects arterial endothelial cells from BMP4 apoptosis [54].

BMP9 and BMP10 are also capable of exerting antiangiogenic effects, potently inhibiting basic fibroblast growth factor-stimulated proliferation and migration of BAECs, VEGFinduced formation of tubular endothelial cell structures in a bone-explant angiogenesis assay [55], and endothelial cell migration and growth in a mouse sponge angiogenesis assay in response to basic fibroblast growth factor [56,57 $]$. In this assay, BMP9 not only inhibits sprouting angiogenesis but also induces destabilization of already formed vessels [57 $]$.

\section{Conclusion}

The role of BMPs in embryonic development has been studied extensively in the past decades, but only recently has their role in vasculogenesis been recognized. The presence of both positive and negative BMP-mediated signaling responses in endothelial cells requires further dissection of the mechanisms by which BMPs participate in the control of angiogenesis. Understanding the role of BMPs in blood vessel formation may open up new therapeutic avenues in vascular disease.

\section{Acknowledgments}

We thank Ripal Shah for reviewing and assisting in the design of the figures.

\section{References and recommended reading}

Papers of particular interest, published within the annual period of review, have been highlighted as:

- of special interest

•• of outstanding interest

Additional references related to this topic can also be found in the Current World Literature section in this issue (p. 229).

1. Urist MR. Bone: formation by autoinduction. Science. 1965; 150:893-899. [PubMed: 5319761]

2. Mishina Y, Suzuki A, Ueno N, Behringer RR. Bmpr encodes a type I bone morphogenetic protein receptor that is essential for gastrulation during mouse embryogenesis. Genes Dev. 1995; 9:30273037. [PubMed: 8543149]

3. Winnier G, Blessing M, Labosky PA, Hogan BL. Bone morphogenetic protein-4 is required for mesoderm formation and patterning in the mouse. Genes Dev. 1995; 9:2105-2116. [PubMed: 7657163]

4. Lechleider RJ, Ryan JL, Garrett L, et al. Targeted mutagenesis of Smad1 reveals an essential role in chorioallantoic fusion. Dev Biol. 2001; 240:157-167. [PubMed: 11784053]

5. Tremblay KD, Dunn NR, Robertson EJ. Mouse embryos lacking Smad1 signals display defects in extra-embryonic tissues and germ cell formation. Development. 2001; 128:3609-3621. [PubMed: 11566864]

6. Chang H, Huylebroeck D, Verschueren K, et al. Smad5 knockout mice die at mid-gestation due to multiple embryonic and extraembryonic defects. Development. 1999; 126:1631-1642. [PubMed: 10079226]

7. Yang X, Castilla LH, Xu X, et al. Angiogenesis defects and mesenchymal apoptosis in mice lacking SMAD5. Development. 1999; 126:1571-1580. [PubMed: 10079220] 
8. Deckers MM, van Bezooijen RL, van der Horst G, et al. Bone morphogenetic proteins stimulate angiogenesis through osteoblast-derived vascular endothelial growth factor A. Endocrinology. 2002; 143:1545-1553. [PubMed: 11897714]

9. Avsian-Kretchmer O, Hsueh AJ. Comparative genomic analysis of the eight-membered ring cystine knot-containing bone morphogenetic protein antagonists. Mol Endocrinol. 2004; 18:1-12. [PubMed: 14525956]

10. Larrain J, Oelgeschlager M, Ketpura NI, et al. Proteolytic cleavage of chordin as a switch for the dual activities of twisted gastrulation in BMP signaling. Development. 2001; 128:4439-4447. [PubMed: 11714670]

11. Shimmi O, Umulis D, Othmer H, O'Connor MB. Facilitated transport of a Dpp/Scw heterodimer by Sog/Tsg leads to robust patterning of the Drosophila blastoderm embryo. Cell. 2005; 120:873886. [PubMed: 15797386]

12. O'Connor MB, Umulis D, Othmer HG, Blair SS. Shaping BMP morphogen gradients in the Drosophila embryo and pupal wing. Development. 2006; 133:183-193. [PubMed: 16368928]

13. Ikeya M, Kawada M, Kiyonari H, et al. Essential pro-Bmp roles of crossveinless 2 in mouse organogenesis. Development. 2006; 133:4463-4473. [PubMed: 17035289]

14. Rentzsch F, Zhang J, Kramer C, et al. Crossveinless 2 is an essential positive feedback regulator of Bmp signaling during zebrafish gastrulation. Development. 2006; 133:801-811. [PubMed: 16439480]

15. Moser M, Binder O, Wu Y, et al. BMPER, a novel endothelial cell precursor-derived protein, antagonizes bone morphogenetic protein signaling and endothelial cell differentiation. Mol Cell Biol. 2003; 23:5664-5679. [PubMed: 12897139]

16. Coles E, Christiansen J, Economou A, et al. A vertebrate crossveinless 2 homologue modulates BMP activity and neural crest cell migration. Development. 2004; 131:5309-5317. [PubMed: 15456729]

17. Binnerts ME, Wen X, Cante-Barrett K, et al. Human crossveinless-2 is a novel inhibitor of bone morphogenetic proteins. Biochem Biophys Res Commun. 2004; 315:272-280. [PubMed: 14766204]

18••. Serpe M, Umulis D, Ralston A, et al. The BMP-binding protein crossveinless 2 is a short-range, concentration-dependent, biphasic modulator of BMP signaling in Drosophila. Dev Cell. 2008; 14:940-953. Description of a biphasic response to CV2 concentration in Drosophila. The authors show how the concentration or type of BMP present can determine CV2 actions. [PubMed: 18539121]

19••. Heinke J, Wehofsits L, Zhou Q, et al. BMPER is an endothelial cell regulator and controls bone morphogenetic protein-4-dependent angiogenesis. Circ Res. 2008; 103:804-812. Description of biphasic response to BMPER concentration in endothelial cells. BMPER regulates BMP-4 angiogenic role and induces Erk1/2 activation. [PubMed: 18787191]

20. Zhang JL, Qiu LY, Kotzsch A, et al. Crystal structure analysis reveals how the chordin family member crossveinless 2 blocks BMP-2 receptor binding. Dev Cell. 2008; 14:739-750. [PubMed: 18477456]

21 . Ambrosio AL, Taelman VF, Lee HX, et al. Crossveinless-2 Is a BMP feedback inhibitor that binds Chordin/BMP to regulate Xenopus embryonic patterning. Dev Cell. 2008; 15:248-260. A combination of in-vitro and in-vivo studies show that CV2 can regulate chordin actions on BMP signaling. [PubMed: 18694564]

22. Balemans W, Van Hul W. Extracellular regulation of BMP signaling in vertebrates: a cocktail of modulators. Dev Biol. 2002; 250:231-250. [PubMed: 12376100]

23. Sun J, Zhuang FF, Mullersman JE, et al. BMP4 activation and secretion are negatively regulated by an intracellular gremlin-BMP4 interaction. J Biol Chem. 2006; 281:29349-29356. [PubMed: 16880207]

24•. Stabile H, Mitola S, Moroni E, et al. Bone morphogenic protein antagonist Drm/gremlin is a novel proangiogenic factor. Blood. 2007; 109:1834-1840. Evidence of gremlin-BMP-independent proangiogenic actions through interaction with a membrane protein and induction of a tyrosine phosphorylation pattern in endothelial cells. [PubMed: 17077323] 
25. Mitola S, Moroni E, Ravelli C, et al. Angiopoietin-1 mediates the proangiogenic activity of the bone morphogenic protein antagonist Drm. Blood. 2008; 112:1154-1157. [PubMed: 18505784]

26. ten Dijke P, Arthur HM. Extracellular control of TGFbeta signalling in vascular development and disease. Nat Rev Mol Cell Biol. 2007; 8:857-869. [PubMed: 17895899]

27. Murshed M, Schinke T, McKee MD, Karsenty G. Extracellular matrix mineralization is regulated locally; different roles of two gla-containing proteins. J Cell Biol. 2004; 165:625-630. [PubMed: 15184399]

28. Bostrom K, Zebboudj AF, Yao Y, et al. Matrix GLA protein stimulates VEGF expression through increased transforming growth factor-beta1 activity in endothelial cells. J Biol Chem. 2004; 279:52904-52913. [PubMed: 15456771]

29. Yao Y, Zebboudj AF, Shao E, et al. Regulation of bone morphogenetic protein-4 by matrix GLA protein in vascular endothelial cells involves activin-like kinase receptor 1. J Biol Chem. 2006; 281:33921-33930. [PubMed: 16950789]

30. Adelman CA, Chattopadhyay S, Bieker JJ. The BMP/BMPR/Smad pathway directs expression of the erythroid-specific EKLF and GATA1 transcription factors during embryoid body differentiation in serum-free media. Development. 2002; 129:539-549. [PubMed: 11807044]

31. Walmsley M, Ciau-Uitz A, Patient R. Adult and embryonic blood and endothelium derive from distinct precursor populations which are differentially programmed by BMP in Xenopus. Development. 2002; 129:5683-5695. [PubMed: 12421708]

32. Valdimarsdottir G, Goumans MJ, Rosendahl A, et al. Stimulation of Id1 expression by bone morphogenetic protein is sufficient and necessary for bone morphogenetic protein-induced activation of endothelial cells. Circulation. 2002; 106:2263-2270. [PubMed: 12390958]

33. Langenfeld EM, Langenfeld J. Bone morphogenetic protein-2 stimulates angiogenesis in developing tumors. Mol Cancer Res. 2004; 2:141-149. [PubMed: 15037653]

34. Raida M, Clement JH, Leek RD, et al. Bone morphogenetic protein 2 (BMP-2) and induction of tumor angiogenesis. J Cancer Res Clin Oncol. 2005; 131:741-750. [PubMed: 16136355]

35. Rothhammer T, Bataille F, Spruss T, et al. Functional implication of BMP4 expression on angiogenesis in malignant melanoma. Oncogene. 2007; 26:4158-4170. [PubMed: 17173062]

36. Ren R, Charles PC, Zhang C, et al. Gene expression profiles identify a role for cyclooxygenase 2dependent prostanoid generation in BMP6-induced angiogenic responses. Blood. 2007; 109:28472853. [PubMed: 17119124]

37. Koki AT, Masferrer JL. Celecoxib: a specific COX-2 inhibitor with anticancer properties. Cancer Control. 2002; 9 (2 Suppl):28-35. [PubMed: 11965228]

38. Bolli R, Shinmura K, Tang XL, et al. Discovery of a new function of cyclooxygenase (COX)-2: $\mathrm{COX}-2$ is a cardioprotective protein that alleviates ischemia/reperfusion injury and mediates the late phase of preconditioning. Cardiovasc Res. 2002; 55:506-519. [PubMed: 12160947]

39•. Pi X, Ren R, Kelley R, et al. Sequential roles for myosin-X in BMP6-dependent filopodial extension, migration, and activation of BMP receptors. J Cell Biol. 2007; 179:1569-1582. A microarray analysis that identifies $M y o X$ as a new BMP target gene which mediates BMPdependent filopodial assembly and Smad activation. [PubMed: 18158328]

40. Derynck R, Zhang YE. Smad-dependent and Smad-independent pathways in TGF-beta family signalling. Nature. 2003; 425:577-584. [PubMed: 14534577]

41. Nohe A, Keating E, Knaus P, Petersen NO. Signal transduction of bone morphogenetic protein receptors. Cell Signal. 2004; 16:291-299. [PubMed: 14687659]

42. Gazzerro E, Canalis E. Bone morphogenetic proteins and their antagonists. Rev Endocr Metab Disord. 2006; 7:51-65. [PubMed: 17029022]

43. Zhou Q, Heinke J, Vargas A, et al. ERK signaling is a central regulator for BMP-4 dependent capillary sprouting. Cardiovasc Res. 2007; 76:390-399. The authors provide evidence that BMP-4 activates Smad and Erk phosphorylation in endothelial cells. Capillary sprouting induced by BMP-4 is dependent on ERK phosphorylation. [PubMed: 17850776]

44. Kretzschmar M, Doody J, Massague J. Opposing BMP and EGF signalling pathways converge on the TGF-beta family mediator Smad1. Nature. 1997; 389:618-622. [PubMed: 9335504] 
45. Hayashida T, Decaestecker M, Schnaper HW. Cross-talk between ERK MAP kinase and Smad signaling pathways enhances TGF-beta-dependent responses in human mesangial cells. FASEB J. 2003; 17:1576-1578. [PubMed: 12824291]

46. Aubin J, Davy A, Soriano P. In vivo convergence of BMP and MAPK signaling pathways: impact of differential Smad1 phosphorylation on development and homeostasis. Genes Dev. 2004; 18:1482-1494. [PubMed: 15198985]

47. Sapkota G, Alarcon C, Spagnoli FM, et al. Balancing BMP signaling through integrated inputs into the Smad1 linker. Mol Cell. 2007; 25:441-454. [PubMed: 17289590]

48•. Fuentealba LC, Eivers E, Ikeda A, et al. Integrating patterning signals: Wnt/GSK3 regulates the duration of the BMP/Smad1 signal. Cell. 2007; 131:980-993. This study describes how Smad1 phosphorylation by GSK3 serves to integrate BMP and Wnt signaling pathways. [PubMed: 18045539]

49••. Davis BN, Hilyard AC, Lagna G, Hata A. SMAD proteins control DROSHA-mediated microRNA maturation. Nature. 2008; 454:56-61. This study elucidates a new mechanism by which BMP and TGF $\beta$ extra-cellular signaling direct cell differentiation via posttranslational regulation of miRNA expression. [PubMed: 18548003]

50. Scalbert E, Bril A. Implication of microRNAs in the cardiovascular system. Curr Opin Pharmacol. 2008; 8:181-188. [PubMed: 18243792]

51. Mathura JR Jr, Jafari N, Chang JT, et al. Bone morphogenetic proteins-2 and -4: negative growth regulators in adult retinal pigmented epithelium. Invest Ophthalmol Vis Sci. 2000; 41:592-600. [PubMed: 10670493]

52. Kane R, Godson C, O'Brien C. Chordin-like 1, a bone morphogenetic protein-4 antagonist, is upregulated by hypoxia in human retinal pericytes and plays a role in regulating angiogenesis. Mol Vis. 2008; 14:1138-1148. [PubMed: 18587495]

53. Kiyono M, Shibuya M. Bone morphogenetic protein 4 mediates apoptosis of capillary endothelial cells during rat pupillary membrane regression. Mol Cell Biol. 2003; 23:4627-4636. [PubMed: 12808102]

54. Kiyono M, Shibuya M. Inhibitory Smad transcription factors protect arterial endothelial cells from apoptosis induced by BMP4. Oncogene. 2006; 25:7131-7137. [PubMed: 16732319]

55. Scharpfenecker M, van Dinther M, Liu Z, et al. BMP-9 signals via ALK1 and inhibits bFGFinduced endothelial cell proliferation and VEGF-stimulated angiogenesis. J Cell Sci. 2007; 120 (Pt 6):964-972. [PubMed: 17311849]

56. David L, Mallet C, Mazerbourg S, et al. Identification of BMP9 and BMP10 as functional activators of the orphan activin receptor-like kinase 1 (ALK1) in endothelial cells. Blood. 2007; 109:1953-1961. [PubMed: 17068149]

57 . David L, Mallet C, Keramidas M, et al. Bone morphogenetic protein-9 is a circulating vascular quiescence factor. Circ Res. 2008; 102:914-922. BMP-9 is found in sera and plasma from healthy humans and strongly inhibits sprouting angiogenesis, likely controlling adult blood vessel quiescence. [PubMed: 18309101] 


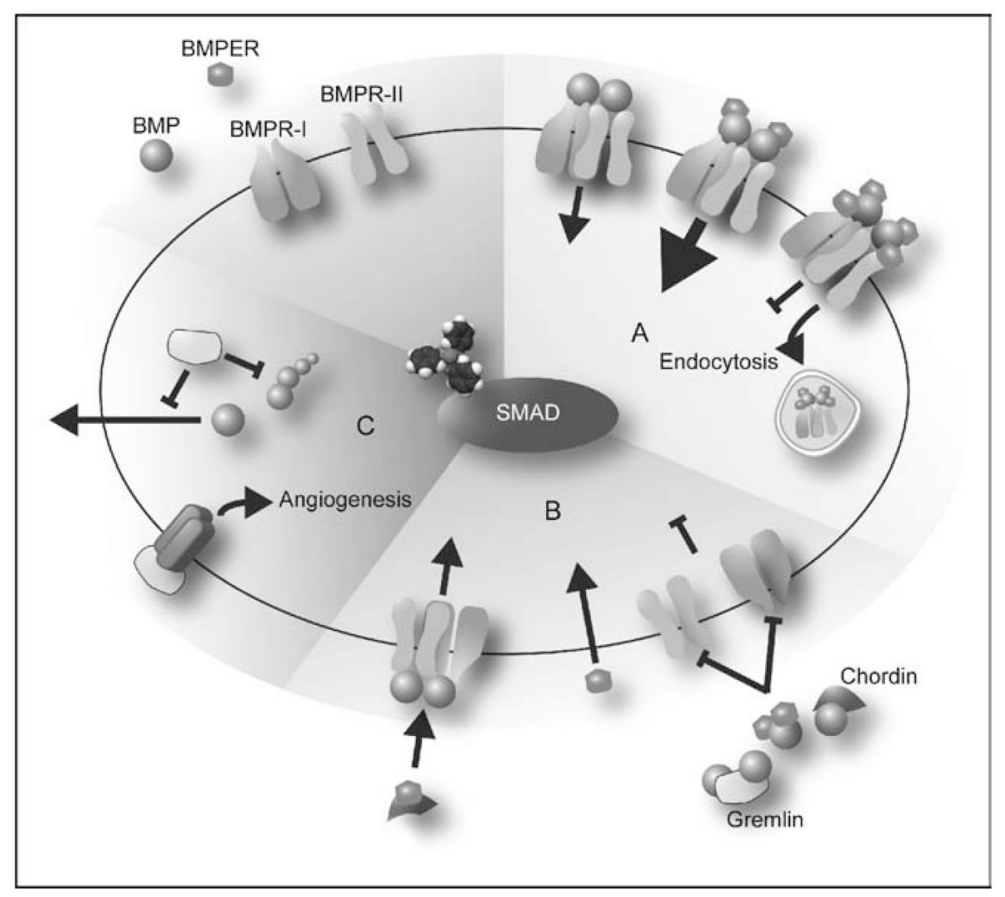

Figure 1. Proposed model for bone morphogenetic protein endothelial cell precursor-derived regulator and gremlin actions as bone morphogenetic protein agonists or antagonists (a) (Yellow) Moderate levels of BMPER (ratio BMPER:BMP smaller than 2: 1) enhance BMP signaling possibly by moving BMPs from the extracellular space onto receptors. Higher levels of BMPER (ratios greater than 2: 1) block BMP signaling by increasing endocytosis of the complex BMPER-BMP. (b) (Green) BMPER, chordin, and gremlin bind BMP, blocking the interaction of BMP with its receptors. BMPER pro-BMP actions would be independent of BMP interaction by physically binding and blocking chordin actions or other mechanisms. (c) (Red) When gremlin is produced in the same cell as BMP, it can block maturation and secretion of BMP. In addition, gremlin has proangiogenic activity independent of BMP through interaction with a membrane receptor. BMP, bone morphogenetic protein; BMPER, bone morphogenetic protein endothelial cell precursorderived regulator. 


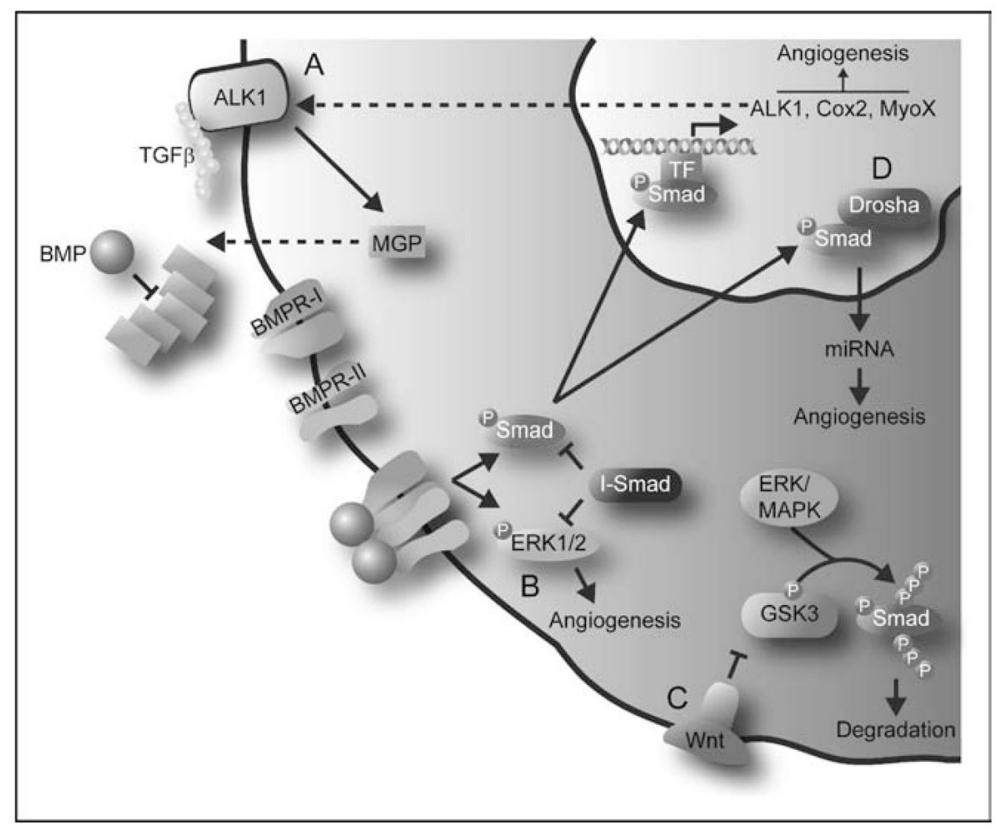

Figure 2. Recent additions to the repertoire of regulatory mechanisms of bone morphogenetic protein signaling

(a) BMP signaling increases expression of ALK1, which when activated by TGF $\beta$ induces expression of the ECM component MGP. Increasing levels of MGP eventually sequester BMP, thereby providing a negative feedback loop. (b) BMP can promote angiogenesis through phosphorylation of Smads and Erk. Crosstalk between these two pathways occurs through the action of inhibitory Smads. (c) GSK3 and ERK/MAPK sequential phosphorylation at the linker domain of Smad proteins leads to its degradation, thereby regulating BMP signaling. Wnt signaling, through inhibition of GSK3, can rescue BMP signaling. (d) Activated Smads interact with the DROSHA component of the nuclear miRNA processing machinery. This interaction increases the production of miRNAs involved in vascular development. ALK1, activin receptor-like kinase 1; BMP, bone morphogenetic protein; Cox2, cycloox-ygenase 2; ECM, extracellular matrix; ERK, extracellular signal-regulated kinase; GSK3, glycogen synthase kinase 3; MAPK, mitogenactivated protein kinase; MGP, matrix gamma-carboxyglutamate protein; miRNA, microRNA; MyoX, myosin-X; TGF $\beta$, transforming growth factor $\beta$. 